\title{
Design of the 'Up2U' Domestic Abuse Perpetrator Programme
}

\author{
Dominic A. S. Pearson* \\ Department of Psychology, University of Portsmouth, Portsmouth, England
}

Amy Ford

Portsmouth City Council, Portsmouth, England

Accepted for publication in Journal of Aggression, Conflict and Peace Research $4^{\text {th }}$ August 2017

* Corresponding author. University of Portsmouth, King Henry Building, King Henry I Street, Portsmouth, United Kingdom, PO1 2DY. Tel: 0044 (0)2392 846635, Fax: 0044 (0)2392 846300, Email:

dominic.pearson@port.ac.uk 


\section{Design of the 'Up2U' Domestic Abuse Perpetrator Programme}

\section{Abstract}

Purpose. This paper outlines the development, structure, and implementation of a new programme for domestic abuse (DA) perpetrators.

Approach. A needs-led DA perpetrator programme is proposed, named 'Up2U: Creating Healthy Relationships' (Up2U). The background to Up2U, its aims, configuration, and delivery methods are presented. To illustrate Up2U, the targets for change and referral population in the development site are discussed. Furthermore, the paper reflects on some of the implementation decisions and the steps taken towards evaluating the impact of Up2U in the development site.

Research/practical implications. Research supports provision of treatment targeting perpetrators' criminogenic needs, delivered with responsivity to their learning styles, at an intensity that matches their risk. Change on treatment targets can be evaluated in the context of differences in recidivism outcomes to help assess whether impact can be attributed to the programme. It can also serve as a more proximal index of success/failure for individual clients. Such implementation and evaluation decisions are a benefit of the present researcherpractitioner partnership.

Originality/value. Up2 $\mathrm{U}$ is innovative by taking a risk and needs-led rather than a gendered model of DA treatment, and this new evidence-based approach may reduce partner abuse. This is the first paper to outline Up2U's structure, content, implementation, and measurement.

Keywords. Batterer intervention ' Evidence-based treatment $\cdot$ Intimate partner violence $\cdot$ Offending behaviour programmes $\cdot$ Randomised Controlled Trial $\cdot$ RCT $\cdot$ Research design $\cdot$ Risk-Needs-Responsivity $\cdot$ Spousal assault 
Partner violence is widely recognised as an all-too-common societal problem, and a major cause of harm and death (Office-for-National-Statistics [ONS], 2016). Representative surveys indicate that around $20 \%$ of people experience domestic abuse (DA), and 6-22\% report DA annually with the higher rates experienced in low income lone parent households (ONS, 2016). The majority of incidents are reported by the minority repeatedly victimised.

However, due to limited evaluation studies, the field of DA perpetrator treatment is currently in danger of a 'nothing works' position similar to that historically experienced in sexual offender treatment (Furby et al., 1989). Systematic reviews have not found current approaches to DA treatment to be demonstrably effective regarding their ability to reduce future violence (Babcock et al., 2004; Feder et al., 2008; Stover et al., 2009). This may be due to a lack of focus on risk factors: DA treatment is provided predominantly using programmes based on a gender-led model. We propose that the DA field would benefit from the provision and evaluation of a criminogenic needs-led intervention programme. The lack of clear effects in this field must also be understood in the context of the state of the research evidence. On the one hand there are too few evaluation studies, but on the other, the studies that do exist have designs with limited methodological rigour. A key argument of this paper concerns the need to provide well controlled evaluations that suit local delivery arrangements. Deficiencies in both aspects, treatment model and evaluation design, are argued to be responsible for the current lack of effects in DA perpetrator treatment. Each aspect is addressed in turn below in introducing the Up2U programme, which we are implementing within a Randomised Controlled Trial in Portsmouth, England.

\section{Need for a New Perpetrator Programme}

The prevailing Duluth model in the DA field takes a socio-cultural perspective assuming that male abusers are socialised to be dominant and therefore entitled to control women into subservience (Pence and Paymar, 1993). According to Dutton and Corvo's (2006) critique of the application of this "monolithic model" (p.461) of male domination and instrumental violence, the emphasis on male socialisation and control of women is often presumed - to the exclusion of other social and psychological factors contributing to abuse. Whereas the Duluth model sees factors such as anger and substance misuse as disingenuous excuses for behaviour, a 
RUNNING HEAD: DESIGN OF THE UP2U DOMESTIC ABUSE PERPETRATOR PROGRAMME

psychological approach views them as dynamic risk factors for recidivism in some subsets of offenders (McMurran and Gilchrist, 2008). The traditional view of considering all offenders as a homogenous group of instrumentally controlling abusers overlooks relevant targets for change that may alter the probability of recidivism. This is therefore a key difference that may account for unconvincing results in evaluations of perpetrator programmes.

\section{The requirement for Criminogenic needs-led intervention}

Over the past 30 years a large body of research evidence has accumulated in determining 'what works' in offender rehabilitation. This evidence suggests that empirically validated risk assessment tools should be used to screen offenders into appropriate quantity/duration of service (the risk principle), targets for change should be selected so that intervention focusses on factors that are empirically linked to criminal behaviour (the need principle), and services should be designed and delivered based on a cognitive social learning theory of the acquisition and maintenance of offending (the responsivity principle). These are the empirically supported RiskNeed-Responsivity (RNR) principles of effective intervention in offender rehabilitation (Bonta and Andrews, 2017; Landenberger and Lipsey, 2005; Smith et al., 2009). Reductions in recidivism correlate with the extent to which the principles are implemented in practice as they were intended in design, ranging from a net criminogenic effect when no principles are met, to a $26 \%$ reduction in recidivism when there is sound adherence to all three principles (Bonta and Andrews, 2017).

The design of a perpetrator programme must therefore target factors that are empirically linked to DA. Research suggests that a set of specific variables increases risk of violence in DA perpetrators, including past violence, young age, unstable lifestyle, and prior criminal history (Hart et al., 1994; Hanson and Wallace-Capretta, 2004; Stith et al., 2004). Thus, the same variables that predict violent recidivism in general offenders (Gendreau et al., 1996; Monahan, 1981) predict recidivism in DA perpetrators. The presence of precipitating circumstances, such as relationship problems, increases the probability of perpetrating DA among those with higher levels of these general risk factors for violence.

Based on the findings of meta-analytic studies, the RNR model appears to have broad applicability across a variety of offender subtypes and criminal behaviours. This includes young 
RUNNING HEAD: DESIGN OF THE UP2U DOMESTIC ABUSE PERPETRATOR PROGRAMME

offenders (Dowden and Andrews, 1999a), and women offenders (Dowden and Andrews, 1999b). Adherence to the principles is relevant in treatment of both violent offending (Dowden and Andrews, 2000) and sexual offending (Hanson et al., 2009). Dowden and Andrews (2000) completed a meta-analysis of 34 evaluations of violence reduction programmes. Target offence behaviours included general violence, as well as sexual and domestic assaults. The effect size for RNR-based interventions was $r=.20$, corresponding to recidivism rates of $40 \%$ and $60 \%$ for intervention and control groups respectively. Consistent with the RNR tenet that it is important to target the density of criminogenic needs, there was a strong correlation $(r=.69)$ between the number of criminogenic needs targeted in treatment and the recidivism reduction effect size. There is therefore optimism that providing programming that is consistent with the RNR model of appropriate treatment should also reduce violent recidivism in DA perpetrators.

\section{Up2U: Creating Healthy Relationships (Up2U)}

As a result of these recommendations a new structured programme, Up2U, was developed by Portsmouth City Council. Consistent with the RNR principles, configuration of Up2U content and duration depends on the participant's assessed characteristics. Thus, the intensity of the programme is determined by the participant's risk level, programme modules are matched to the participant's risk-related needs, and treatment is based on Cognitive-Behavioural Therapy (CBT) to ensure general responsivity to offender learning with attention to specific differences between participants e.g., in strengths. In providing intervention based on RNR, Up2U contrasts with the Duluth model (Pence and Paymar, 1993), instead recognising that people use DA for different underlying reasons. These may range from learned behaviour, including but not restricted to attitudes that promote male dominance and control, to lack of skills in emotional management and conflict resolution. These targets for change are each discussed below in terms of their potential status as criminogenic needs.

\section{Interpersonal problem-solving skills deficits.}

Problem-solving skills such as communication, negotiation, and responding to criticism are likely to be beneficial in developing healthy relationships. Proposed deficits in these skills in high conflict marital interactions have been linked to the use of violence (e.g., Ronan et al., 
RUNNING HEAD: DESIGN OF THE Up2U DOMESTIC ABUSE PERPETRATOR PROGRAMME

2004). Interviews with formerly abusive men have also highlighted improved listening and conflict management skills (Scott and Wolfe, 2000).

CBT programmes that specifically target social problem-solving skills among general offenders have demonstrated improvements in intermediary treatment targets including impulsivity levels and locus of control (LoC) (McDougall et al., 2009), problem-solving skills (McMurran et al., 2001), frustration tolerance, social conformity, and critical reasoning (Tapp et al., 2009). LoC has been found to correlate with measures of social problem-solving ability and self-esteem, both in the wider personality literature and with offenders (Huntley et al., 2012). LoC is the extent to which a client believes he/she has control over his/her life and how he/she attributes causes to events. Recidivism outcome studies suggest key features of effective interventions are interpersonal problem-solving and anger control (Landenberger and Lipsey, 2005).

\section{Emotional management problems.}

There is good support in systematic reviews for the idea that male and female DA perpetrators show a greater propensity for anger across situations and express this outwardly relative to nonviolent individuals (e.g., Birkley and Eckhardt, 2015; Capaldi et al., 2012). A heightened propensity to experience anger is hypothesised to cause changes to cognition, arousal and affect that increase the likelihood of aggressive behaviour occurring in particular circumstances (Anderson and Bushman, 2002). Perpetrators are expected to show an increased tendency for anger to lead to violence when they are under the influence of drugs, alcohol, or mental illness symptoms. Based on clinical presentation of 139 men attending community DA treatment, Murphy et al. (2007) identified three distinct sub-groups: pathological anger (19\%); low anger control (31\%); and normal anger (50\%). After six months post-treatment follow-up, compared to the normal anger group the problematic anger men had significantly higher rates of physical aggression and injury, according to partner reports. A link has also been established between poor anger control and propensity to drop-out of treatment (Eckhardt et al., 2008). This is important given the strong relation across studies between the predictors of drop-out and the predictors of recidivism (Olver et al., 2011). Lack of emotional competencies such as the ability to identify and control emotions, and lack of strategies for soothing and re-appraisal, may feed 
RUNNING HEAD: DESIGN OF THE Up2U DOMESTIC ABUSE PERPETRATOR PROGRAMME

into an overall difficulty to self-manage. There is therefore expected to be an overlap with improvements in interpersonal problem-solving skills.

\section{Pro-criminal attitudes.}

The key factors underpinning all criminogenic needs are antisocial cognitions, values, and behaviours. These attitudes and values may or may not be initiating factors for abusive behaviour, but are likely to be involved in maintaining such behaviour. For example, in Hanson and Wallace-Capretta (2004) a factor discriminating DA men who violently reoffended from those that did not was the presence post-treatment of a negative attitude to treatment providers: the effect size was double that of pro-abuse attitudes (e.g., hostile masculinity). A review of within-treatment change studies found that reductions in general anti-social attitudes were associated with reduced re-offending across the domains of cognition, violence, and substance misuse (Serin et al., 2013).

Weak effects of pro-abuse attitudes supports the conflicting results of reviews considering this factor. Sugarman and Frankel (1996) concluded that DA perpetrators could not be differentiated from non-abusive men on the basis of traditional gender attitudes or gender schemas, while two other reviews have found sex-role attitudes to be low-to-moderate proximal predictors (Capaldi et al. 2012; Stith et al., 2004). Bowen et al. (2008) found a reduction within-treatment in DA supportive attitudes but could not link this to changes in reoffending. This contrasts with the above evidence of outcome validity of within-treatment change in general anti-social attitudes.

In proposing that males and females have similar criminogenic needs and can benefit from similar crime intervention models, Up2U supports gender-neutral theory. Thus, males may be more likely than females to be engaged in antisocial behaviour generally, but gender will have a minimal effect on recidivism likelihood after considering the density of criminogenic needs in individual cases (Bonta and Andrews, 2017). Consistent with effective practice principles gender is however viewed to be an important Responsivity consideration with important implications for programme design, intervention planning, and service delivery. This is discussed next in the programme description.

\section{Programme Design}


RUNNING HEAD: DESIGN OF THE UP2U DOMESTIC ABUSE PERPETRATOR PROGRAMME

Programme aims.

Up2U is designed as an intervention for people who use DA behaviours in their intimate relationships. It aims to help these individuals to recognise and stop using abusive behaviours by learning how to manage the way they think, feel, and then act. This is expected to result in healthier relationships, reduced feelings of guilt and shame, and improved outcomes for families including less involvement with the police and other services. The final outcome goal of the programme is therefore a reduction in family violence.

\section{Assessment and targeting.}

As Up2U is a needs-based intervention, the programme can be tailored to work with both males and females from the age of 16 and can be delivered to people who use DA in same sex relationships. To be eligible a person must accept that they use abusive or unhealthy behaviours in their relationship and want to change this. Referrals are from general medical practitioners, the police, children's social care, and via self-referral.

The main assessment tool used is the Level of Service/Risk, Need, Responsivity (LS/RNR: Andrews et al., 2008). The LS/RNR provides an actuarial assessment of future risk of offending or rule breaking behaviours and enables identification of target areas for change that may be linked with future abusive behaviours. It also directs consideration of Responsivity factors. Higher scores indicate greater risk and a need for more intensive service. The programme also uses the Spousal Assault Risk Assessment (SARA: Kropp et al., 1999) which is the most widely used structured judgement tool for DA perpetrator evaluations. The SARA structures an assessment of the risk of domestic violence specifically and assists with monitoring and victim safety planning [1].

Table 1 shows participant characteristics for the first 100 cases referred to the trial in Portsmouth in the first year and two months. More men were referred than women, and on average men were older and less often employed than women. However there was no difference between the groups in criminal risk. Women were more often referred as part of a dyadic referral, with both partners recognising responsibility for perpetrating relationship abuse. There was no difference between the proportion of men (48.65\% [36/74]) and women (53.85\% [14/26]) allocated to Up2U within the trial $\left(\chi^{2}=.208, \mathrm{df}=1, p=.648\right)$. 
[Table 1 about here]

\section{Mode and intensity of delivery.}

$\mathrm{Up} 2 \mathrm{U}$ is delivered in a one-to-one format, to allow optimal individualisation of content. When someone is accepted onto Up2U, one-to-one support is offered to their partner/ex-partner to ensure ongoing safety and risk management. Partner support is delivered by the City Council's DA victims' services, while perpetrator programming is delivered by Up2U facilitators. Facilitator training takes place over ten days and involves instruction on the RNR principles followed by interactive activities (e.g., role play). Clinical follow-up is provided to support integrity of training transfer.

In line with the risk principle of effective intervention the programme has a variable duration. Depending on the risk/needs assessment the length of Up2U can range from six to 40 one-hour sessions, with the option of extended sessions where risk and need indicate. High and very high risk clients receive all relevant treatment modules while low risk clients receive only the Engagement \& Assessment module and the Relationships module (see below). The maximum time in intervention is likely to be twelve months if all aspects are undertaken, though average intervention time is around six months.

\section{Treatment pathways and targets.}

Depending on the assessment of needs, modules are selected from: Assessment \& Engagement; Relationships; Skills for Change; Thinking, Feeling \& Behaviour; Skills for Change - extended; Stalking Behaviours (targeted sessions); Unhealthy Sexualised Behaviours (targeted sessions); and Substance Misuse (targeted sessions). Relapse prevention runs alongside all modules to ensure each client has a workable plan to prevent future abuse. At the end of treatment all clients are given 'moving on' referrals to ensure that all their needs are addressed.

In the first module 'Assessment \& Engagement', motivational interviewing (MI) techniques are used to promote positive engagement with the programme, to build on motivation to change, and to build rapport, in recognition that clients present with varying levels of readiness to change (Miller and Rollnick, 2002). MI also serves to optimise the depth and quality of information 
provided by clients, which is then used to update the initial assessment and finalise the treatment pathway. The Relationships module then aims to help clients identify any unhealthy or abusive behaviours they use in their relationships. The main focus is on their relationships with intimate partner(s); however there are also sessions that focus on their relationships with their children, family, and friends. The module compliments CBT with additional behavioural and attitudinal concepts from attachment theory and transactional analysis, in particular Eric Berne's (1968) 'I'm OK You're OK' model.

As a minimum medium-risk clients also complete the 'Skills for Change' module. This focuses on skills to help them use healthy behaviours within their relationships. In response to research discussed in the previous section identifying deficits in emotional recognition and management in violent offenders, pro-criminal attitudes, poor problem solving skills, and an inability to assertively manage conflict situations, Skills for Change includes sessions on recognising emotions, dealing with anger, aggression and stressful situations, and coping with jealousy.

'Thinking, Feeling \& Behaviour' then helps higher-risk clients to link these three processes. By learning that they are in control of cognitions, participants can challenge their negative ways of thinking and replace them with positive self-instructions that do not lead to negative emotions and abusive behaviours. Through experiential learning, clients are encouraged to create new thinking patterns and actions in place of previous abusive behaviours.

\section{Programme Implementation and Evaluation}

Programmes are always implemented in a context and this section aims to discuss the parameters around implementation including the extent to which these were due to evaluation requirements. As the second author (AF) was trained to postgraduate level in psychology, she was aware of the impact of evaluation requirements on programme implementation, and the consequent need to consider evaluation at the time of implementation rather than afterwards, as is too often the case. We know that programme evaluation can be configured in a way that supports implementation without compromising the validity of the relationship between the programme and its outcomes (e.g., Pearson et al., 2010). On the basis of this experience, a partnership was initiated with the first author. This researcher-practitioner partnership enables the development of evidence-based practice, which is a hallmark of Up2U. 
Evaluators in the field of sexual offender treatment advise that misleading results can be safeguarded against by i) using a high-quality research design to protect against prior betweengroup differences; ii) using an appropriate actuarial measure to control for prior risk across groups; and iii) including in-treatment measures of success/failure in the programme protocol (Marques et al., 2005). These recommendations are used to structure the following section outlining our decisions on implementation for evaluation. At the end of the section we discuss our selection of outcome measures.

\section{Protecting against prior between-group differences.}

The first consideration was the selection of comparison group. This decision is important because an inappropriate comparison group can lead to misattribution of any effects to the programme. Since we aimed to avoid a design whose results could mislead victims to expect protection from the programme, this required a research approach with strong internal validity, i.e., able to isolate the programme as the cause of any difference in violence outcomes. We were aware that observational designs, in which groups are assigned for non-random or 'incidental' reasons, e.g., more appetite for the programme among certain clients or staff, are more vulnerable to inadvertent but outcome relevant non-equivalence between groups such as differing client or staff motivations. A relevant example of this where imbalance could readily occur is in 'stake in conformity'; where less marginal DA perpetrators with more of a stake in community life are more affected by interventions (e.g., Sherman et al., 1992).

We therefore aimed to implement with highly equivalent comparison groups and chose a Randomised Controlled Trial (RCT) as the best means to do this. In the Up2U development site, a city council, there are insufficient resources for all referrals to receive the programme simultaneously. In this circumstance we knew we were likely to require a waiting list, which has been associated with worse outcomes for these cases, since waitlisted clients know that they are not receiving any support (McConaghy, 1999). If treatment brings better outcomes relative to a waiting list, that does not exclude the possibility of the treatment having a placebo effect, i.e., due to beliefs in the inherent effectiveness of any treatment. Clients on a waiting list should arguably be included in the treatment group anyway, as there is an 'intention to treat'. Since there was a lack of resources for the expected number of referrals, limiting access to the programme on a random basis was thought to be the fairest approach (Farrington et al., 2009; Hanson, 1997). We therefore agreed to implement a Randomised Controlled Trial (RCT). 
RUNNING HEAD: DESIGN OF THE UP2U DOMESTIC ABUSE PERPETRATOR PROGRAMME

The programme development site is a city council with voluntary clients. Intentionally restricting Up2U to one-half of these cases was justifiable since we did not know whether the treatment actually reduces victimisation or whether it has harmful effects. This is supported by evidence-based practice reviewers who argue that with otherwise untested programmes, the only ethical option is to provide treatment within a well-controlled evaluative study (Feder et al., 2008; Kenworthy et al., 2004). This allows providers to be clear that the intervention is being tested, and avoids offering victim partners and taxpayers false expectation of safety or protection.

It is important to define what is being received in the control condition. Should the intervention prove effective, then identifying what was being received for non-intervention clients would help discern the baseline over which the intervention is improving. The types of comparison group in the existing and inconclusively effective DA intervention literature, include probation case management (Feder and Dugan, 2002), 40 hours of community services (Davis et al., 2000), treatment no-shows and dropouts (Jones and Gondolf, 2002), and no intervention (Dunford, 2000). In evaluating Up2U we decided that the comparison condition ought to be 'practice-as-usual', i.e., local pre-existing provision for DA perpetrators. For example, in the development site area this included family key-work via Barnardo's Family Intervention Project, substance misuse treatment via the Portsmouth recovery hub, and community mental health services. These services are publicly available but since social care clients are voluntary, keywork or 'case coordination' to signpost these services was not part of practice-as-usual [2].

\section{Measuring between-groups differences in risk.}

A second consideration was to minimise between-groups differences in risk. Such variations may be associated with differences in outcome, and so it was important to measure this using an appropriate actuarial risk measure. This meant one that is empirically supported for its validity in predicting criminal behaviour, and as mentioned earlier we selected the LS/RNR (Andrews et al., 2008). The LS measures are third and fourth-generation risk tools designed for the prediction of recidivism based on the 'Central Eight' risk factors underpinning a general personality and cognitive social learning theory of criminal behaviour (Bonta and Andrews, 2017). These include the domains of criminal history, antisocial attitudes, antisocial personality pattern, 
RUNNING HEAD: DESIGN OF THE Up2U DOMESTIC ABUSE PERPETRATOR PROGRAMME

antisocial associates, substance abuse, family/marital, leisure/recreation, and

education/employment. The LS measures have a strong foundation of research support in

predicting criminal justice outcomes, with large international meta-analyses finding an overall medium effect size in predicting community recidivism (e.g., Campbell et al., 2009; Olver et al., 2014). Importantly Olver et al. (2014) found there were few differences between males and females in effect size magnitude, whether for violent or general recidivism, supporting a genderneutral approach to risk assessment.

\section{Providing measures of success / failure within-treatment.}

A key question to be addressed in evaluation concerns what are the causal risk factors for DA, i.e., the factors that change in treatment among those DA clients that remain offence-free compared to those that re-offend. This has not been established in the research so far, arguably because of the traditional focus on accountability rather than psychological change. The use of pre-post in-treatment measures has been recommended for monitoring process and programme integrity in offender rehabilitation (Andrews et al., 2011; Hanson, 1997; Marques et al., 2005). We therefore included a small number of relevant psychometric change measures.

To measure behavioural self-responsibility we included the Craig Locus of Control (Craig et al., 1984). Low scores indicate a belief that events are under personal control, whilst high scores indicate a belief that external factors control one's life. It was validated originally as a predictor of treatment relapse following a behaviour therapy programme for stutterers. It has not yet been validated against reconviction but research suggests treatment can impact locus of control (e.g., McDougall et al., 2009).

To measure anger control we included the Novaco Anger Scale (NAS) (Novaco, 1994), a well-tested self-report scale. NAS tests i) reactions to provocation, giving scores on cognitive, arousal and behavioural sub-scales, and ii) situations that provoke anger giving scores on sources of annoyance such as disrespectful treatment or frustration/interruption. Change on the NAS has not been found to predict DA after a Duluth-based programme (Bowen et al., 2008).

To measure antisocial attitudes we included Crime-PICS II (Frude et al., 2008). This aims to measure attitude to offending and produces scores on four sub-scales: general attitude to offending, anticipation of re-offending, victim hurt denial, and evaluation of crime as worthwhile. The scale can show significant movement over the period of a programme. Overall, 
RUNNING HEAD: DESIGN OF THE Up2U DOMESTIC ABUSE PERPETRATOR PROGRAMME

Crime PICS II has been reported to be a valid and reliable measure in recent studies, with moderate to high test-retest reliability and internal consistency (Frude et al., 2008; McDougall et al., 2009). Its potential for predicting re-offending has been tested and found encouraging (Raynor, 1998).

Finally to provide a measure of the extent to which the client's responses to the measures were reliable rather than based on self-deception or impression management, we included the Paulhus Deception Scale (PDS) (Paulhus, 1999). The PDS measures the tendency to give socially desirable responses, and has two subscales: Impression Management, and SelfDeception Enhancement. Impression management refers to the tendency of individuals to purposely describe themselves in overly positive terms. Self-Deception Enhancement refers to an unconscious favourability bias and overconfidence akin to narcissism.

\section{Selection of final outcome measures.}

Domestic violence and abuse is defined as "any incident or pattern of incidents of controlling, coercive, threatening behaviour, violence or abuse between those aged 16 or over who are, or have been, intimate partners or family members regardless of gender or sexuality" (Home Office, 2013). There is a need to provide reliable outcome measures of the change in these behaviours following treatment. DA is one of the most under-reported crimes in our criminal justice system (Kershaw et al., 2008). Despite DA conviction rates reaching their highest ever levels in recent years (74\%), approximately one-in-five prosecutions are dropped due to withdrawn or otherwise insufficient evidence (Crown Prosecution Service, 2015). In their longitudinal Cambridge Study in Delinquent Development sample, Piquero and colleagues (2014) found that, by the age of 50, the proportion that had both self-reported IPV and been convicted for a violent offence - most commonly physical fighting in public - was $30.6 \%$ (22/72). The base-rate of officially recorded offending due to DA, and in particular re-offending, is therefore so low that using criminal convictions as the outcome measure in any small-scale study can obscure results. Although using arrests as an outcome is sometimes seen as too unforgiving in measuring re-offending (Latessa and Holsinger, 1998), we chose to track official police records in evaluating DA as this outcome is closer to the abuse behaviour, and is less subject to attrition in criminal justice system processing. 
RUNNING HEAD: DESIGN OF THE UP2U DOMESTIC ABUSE PERPETRATOR PROGRAMME

\section{Conclusions}

The foregoing discussion set out the design of the Up2U programme, and illustrated how we incorporated safeguards against misleading results in the design of Up2U's evaluation. Up2U represents a change to existing practice that is predominantly based on a socio-cultural model of male patriarchy. Despite the evidence across subgroups of offenders favouring treatment that is designed according to the RNR model, Up2U is exceptional in its application of these principles to the treatment of DA perpetrators. While the dynamic validity of risk factors for DA remains to be proven, this is also the case with violent offenders in general due to few studies linking treatment change to recidivism (Serin et al., 2013). The Up2U evaluation project aims to test dynamic validity related to the programme's treatment targets, for the 100 cases described in this paper, offering a contribution to the field regarding DA risk factors.

A further key contribution is the, otherwise rare, provision of an RCT for programme evaluation. This will test the finding from one DV meta-analysis (Babcock et al., 2004) and those with other offender populations also (Beech et al., 2015; Hanson et al., 2009; Weisburd et al., 2001) that the better designed the research study, the less effective the programmes were likely to be. A high quality research design may expose weaknesses either in treatment content or in implementation, that may be disguised by less rigorous methods but which are important to eliminate in the protection of victims. In appreciation of the need for evidence-based DA treatment, Up2U has attracted interest from around the UK, from South England to Scotland. This paper has focussed on the design of the evaluation in Portsmouth, but we anticipate the need for different methodologies for the different contexts in which the programme is now being used.

Research evidence suggests a "cumulative effect" of adherence to the principles of "what works' in reducing recidivism (Smith et al., 2009, p.163). This paper has outlined the measurement of ' risk' in the implementation of Up2U using a validated measure, the LS/RNR. The integrity of the degree to which risk corresponds with treatment dosage can therefore be assessed. In accordance with the 'need' principle, programme design should target factors that are empirically linked to DA recidivism. This paper has set out the treatment targets of Up2U, and their potential status as criminogenic needs. Within-individual change on these treatment targets increases confidence that recidivism outcomes observed are due to the programme. The pattern of individual differences in treatment change can also provide an indication of 
RUNNING HEAD: DESIGN OF THE UP2U DOMESTIC ABUSE PERPETRATOR PROGRAMME

therapeutic integrity, or, pointers for programme development (Hanson, 1997). Regarding the 'responsivity' principle, programme adherence is examined in routine clinical supervision, but also benefits from the researcher-practitioner partnership described in this paper. For example, research expertise has been applied to the collection and analysis of client engagement ('Should I Stay or Should I Go Now?' A Qualitative Study of Completer and Non-Completer Experiences of a Domestic Abuse Perpetrator Programme, manuscript in preparation). Validating integrity and then conducting controlled outcome research is part of developing evidence-based practice (Miller \& Miller, 2015). We argue that the field of DA urgently needs such evidence-based practice and decision-making.

\section{Notes}

1. At present SARA is only validated for male offenders (Kropp \& Hart, 2000). As there are no validated DA assessments for women, Up2U uses SARA 'as designed' alongside other risk measures, including the LS/RNR (Andrews et al., 2008).

2. Subsequent to the first 100 cases, case coordination has been provided by the city council for cases not assigned to the programme.

\section{References}

Anderson, C., and Bushman, B. (2002). "Human aggression." Annual Review of Psychology, 53(1), pp.27-51. https://doi.org/10.1146/annurev.psych.53.100901.135231

Andrews, D.A., Bonta, J., and Wormith, J.S. (2008). The Level of Service/Risk-Need-Responsivity (LS/RNR). Toronto, Ontario, Canada: Multi-Health Systems.

Andrews, D.A., Bonta, J., and Wormith, J.S. (2011). "The Risk-Need-Responsivity (RNR) model: Does adding the Good Lives Model contribute to effective crime prevention?" Criminal Justice and Behavior, 38(7), pp.735-755. doi: 10.1177/0093854811406356

Babcock, J., Green, C., and Robie, C. (2004). "Does batterers' treatment work? A meta-analytic review of domestic violence treatment." Clinical Psychology Review, 23(8), pp.1023-1053. doi:

10.1016/j.cpr.2002.07.001 
RUNNING HEAD: DESIGN OF THE Up2U DOMESTIC ABUSE PERPETRATOR PROGRAMME

Beech, A., Freemantle, N., Power, C., and Fisher, D. (2015). "An examination of potential biases in research designs used to assess the efficacy of sex offender treatment." Journal of Aggression, Conflict and Peace Research, 7(4), pp.204-222. doi: 10.1108/JACPR-01-2015-0154

Berne, E. (1968). Games people play: The psychology of human relationships. London, UK: Penguin.

Birkley, E., and Eckhardt, C. (2015). "Anger, hostility, internalizing negative emotions, and intimate partner violence perpetration: A meta-analytic review." Clinical Psychology Review, 37, pp.4056. http://dx.doi.org/10.1016/j.cpr.2015.01.002

Bonta, J., and Andrews, D.A. (2017). The psychology of criminal conduct ( $6^{\text {th }}$ ed.). New York, NY: Routledge.

Bowen, E., Gilchrist, E., and Beech, A. (2008). "Change in treatment has no relationship with subsequent re-offending in UK domestic violence sample: A preliminary study." International Journal of Offender Therapy and Comparative Criminology, 52(5), pp.598-614. https://doi.org/10.1177/0306624X08319419

Campbell, M., French, S., and Gendreau, P. (2009). "The prediction of violence in adult offenders: A meta-analytic comparison of instruments and methods of assessment." Criminal Justice and Behavior, 36(6), pp.567-590. doi:10.1177/0093854809333610

Capaldi, D., Knoble, N., Shortt, J., and Kim, H. (2012). "A systematic review of risk factors for intimate partner violence." Partner Abuse, 3(2), pp.231-280. doi: 10.1891/1946-6560.3.2.231

Craig, A.R., Franklin, J.A. and Andrews, G. (1984). A scale to measure locus of control of behaviour. British Journal of Medical Psychology, 57(2), pp.173-180. https://doi.org/10.1111/j.20448341.1984.tb01597.x

Crown-Prosecution-Service. (2015). "Violence against women and girls crime report 2014-15." Available from http://www.cps.gov.uk/publications/docs/cps vawg report 2015 amended september 2015 v2. $\underline{\mathrm{pdf}}$

Davis, R.C., Taylor, B.G. and Maxwell, C., 2000. Does Batterer Treatment Reduce Violence? A Randomized Experiment in Brooklyn. Available from https://www.ncjrs.gov/pdffiles1/nij/grants/180772.pdf

Dowden, C., and Andrews, D.A. (1999a). "What works in young offender treatment: A meta-analysis." Forum on Corrections Research, 11(2), pp.21-24.

Dowden, C., and Andrews, D.A. (1999b). "What works for female offenders: A meta-analytic review." Crime \& Delinquency, 45(4), pp.438-452. doi: 10.1177/0011128799045004002

Dowden, C., and Andrews, D.A. (2000). "Effective correctional treatment and violent reoffending: A meta-analysis." Canadian Journal of Criminology, 42, pp.449-467. 
RUNNING HEAD: DESIGN OF THE Up2U DOMESTIC ABUSE PERPETRATOR PROGRAMME

Dunford, F. (2000). "The San Diego navy experiment: An assessment of interventions for men who assault their wives." Journal of Consulting and Clinical Psychology, 68(3), pp.468-476. doi: 10.1037/0022-006X.68.3.468

Dutton, D., and Corvo, K. (2006). "Transforming a flawed policy: A call to revive psychology and science in domestic violence research and practice." Aggression and Violent Behavior, 11(5), pp.457-483. http://dx.doi.org/10.1016/j.avb.2006.01.007

Eckhardt, C., Holtzworth-Munroe, A., Norlander, B., Sibley, A., and Cahill, M. (2008). "Readiness to change, partner violence subtypes, and treatment outcomes among men in treatment for partner assault." Violence and Victims, 23(4), pp.446-475. doi:10.1891/0886-6708.23.4.446

Farrington, D., Loeber, R., and Welsh, B. (2009). "Longitudinal experimental studies in criminology." In A. R. Piquero and D. Weisburd (Eds.), Handbook of quantitative criminology (pp.503-518). New York, NY: Springer.

Feder, L., Austin, S., and Wilson, D. (2008). Court-Mandated Interventions for Individuals Convicted of Domestic Violence. The Campbell Collaboration Library: Available from http://www.campbellcollaboration.org/lib/project/44/.

Feder, L., and Dugan, L. (2002). "A test of the efficacy of court-mandated counseling for domestic violence offenders: The broward experiment." Justice Quarterly, 19(2), pp.343-375. doi: $10.1080 / 07418820200095271$

Frude, N., Honess, T., and Maguire, M. (2008). Crime-PICS II manual. Cardiff, UK. Available from https://g.co/kgs/TjeXLz

Furby, L., Weinrott, M., and Blackshaw, L. (1989). "Sex offender recidivism: A review." Psychological Bulletin, 105(1), pp.3-30. doi: 10.1037/0033-2909.105.1.3

Gendreau, P., Little, T., and Goggin, C. (1996). "A meta-analysis of the predictors of adult offender recidivism: What works!" Criminology, 34, pp.575-608. doi:10.1111/j.1745-

9125.1996.tb01220.x

Hanson, R. (1997). "How to know what works with sexual offenders." Sexual Abuse: A Journal of Research and Treatment, 9(2), pp.129-145. doi:10.1007/bf02674863

Hanson, R., Bourgon, G., Helmus, L., and Hodgson, S. (2009). "The Principles of Effective Correctional Treatment Also Apply To Sexual Offenders: A Meta-Analysis." Criminal Justice and Behavior, 36(9), pp.865-891. doi:10.1177/0093854809338545

Hanson, R., and Wallace-capretta, S. (2004). "Predictors of criminal recidivism among male batterers." Psychology, Crime \& Law, 10(4), pp.413-427. doi:10.1080/10683160310001629283

Hart, S., Kropp, P., Roesch, R., and Ogloff, J. (1994). "Wife assault in community-resident offenders." Canadian Journal of Criminology, 36(4), pp.435-446.

Home Office (2013). Guidance: Domestic violence and abuse. Retrieved from https://www.gov.uk/guidance/domestic-violence-and-abuse 
RUNNING HEAD: DESIGN OF THE Up2U DOMESTIC ABUSE PERPETRATOR PROGRAMME

Huntley, F., Palmer, E., and Wakeling, H. (2012). "Validation of an adaptation of Levenson's Locus of Control scale with adult male incarcerated sexual offenders." Sexual Abuse: A Journal of Research and Treatment, 24(1), pp.46-63. doi:10.1177/1079063211403163

Jones, A., and Gondolf, E. (2002). "Assessing the effect of batterer program completion on reassault: An instrumental variables analysis." Journal of Quantitative Criminology, 18(1), pp.71-98. doi:10.1023/a:1013244929733

Kenworthy, T., Adams, C., Bilby, C., Brooks-Gordon, B., and Fenton, M. (2004). "Psychological interventions for those who have sexually offended or are at risk of offending." Cochrane Database of Systematic Reviews (doi:10.1002/14651858.CD004858): John Wiley \& Sons, Ltd.

Kershaw, C., Nicholas, S. and Walker, A. (2008). Crime in England and Wales 2007/08: Findings from the British Crime Survey and police recorded crime. Home Office Statistical Bulletin, 7(08).

Kropp, P., \& Hart, S. (2000). The Spousal Assault Risk Assessment (SARA) Guide: Reliability and Validity in Adult Male Offenders. Law and Human Behavior, 24, 101-118. https://doi.org/10.1023/A:1005430904495

Kropp, P., Hart, S., Webster, C., and Eaves, D. (1999). The Spousal Assault Risk Assessment: User's guide. Toronto, Canada: Multi-Health Systems Inc.

Landenberger, N., and Lipsey, M. (2005). "The positive effects of cognitive-behavioral programs for offenders: A meta-analysis of factors associated with effective treatment." Journal of Experimental Criminology, 1(4), pp.451-476. doi:10.1007/s11292-005-3541-7

Latessa, E., and Holsinger, A. (1998). "Importance of evaluating correctional programs: Assessing outcome and quality." Corrections Management Quarterly, 2(4), pp.22-29.

Marques, J., Wiederanders, M., Day, D., Nelson, C., and van Ommeren, A. (2005). "Effects of a relapse prevention program on sexual recidivism: Final results from California's Sex Offender Treatment and Evaluation Project (SOTEP)." Sexual Abuse: A Journal of Research and Treatment, 17(1), pp.79-107. doi: 10.1177/107906320501700108

McConaghy, N. (1999). "Methodological issues concerning evaluation of treatment for sexual offenders: Randomization, treatment dropouts, untreated controls, and within-treatment studies." Sexual Abuse: A Journal of Research and Treatment, 11(3), pp.183-193. doi:10.1177/107906329901100302

McDougall, C., Perry, A., Clarbour, J., Bowles, R., and Worthy, G. (2009). "Evaluation of HM prison service Enhanced Thinking Skills programme: Report on the outcomes from a randomised controlled trial." Ministry of Justice Research Series (Vol. 3/09). Available from http://webarchive.nationalarchives.gov.uk/20091009065857/http://www.justice.gov.uk/publicatio ns/docs/report-on-the-outcomes-from-a-randomised-controlled-trial1.pdf

McMurran, M., Fyffe, S., McCarthy, L., Duggan, C., and Latham, A. (2001). "'Stop \& Think!': social problem-solving therapy with personality-disordered offenders." Criminal Behaviour and Mental Health, 11(4), pp.273-285. doi:10.1002/cbm.401 
RUNNING HEAD: DESIGN OF THE Up2U DOMESTIC ABUSE PERPETRATOR PROGRAMME

McMurran, M., and Gilchrist, E. (2008). "Anger control and alcohol use: Appropriate interventions for perpetrators of domestic violence?" Psychology, Crime \& Law, 14(2), pp.107-116. doi:10.1080/10683160701483435

Miller, J., and Miller, H. (2015). "Rethinking program fidelity for criminal justice." Criminology and Public Policy, 14(2), pp.339-349. doi:10.1111/1745-9133.12138

Miller, W., and Rollnick, S. (2002). Motivational Interviewing: Preparing People for Change (2nd ed.). New York, NY: Guilford.

Monahan, J. (1981). Predicting violent behavior: An assessment of clinical techniques. Beverley Hills, CA: Sage.

Murphy, C., Taft, C., and Eckhardt, C. (2007) "Anger problem profiles among partner violent men: Differences in clinical presentation and treatment outcome." Journal of Counselling Psychology, 54(2), 189-200. doi:10.1037/0022-0167.54.2.189

Novaco, R. (1994). "Anger as a risk factor for violence among the mentally disordered." In J. Monahan \& H. J. Steadman (Eds.), Violence and mental disorder: Developments in risk assessment. (pp.2160). Chicago, IL: University of Chicago Press.

Office-for-National-Statistics. (2016). Intimate personal violence and partner abuse. In J. Flatley (Ed.), Compendium: Focus on Violent Crime and Sexual Offences: Year Ending March 2015. Retrieved from https://www.ons.gov.uk/peoplepopulationandcommunity/crimeandjustice/compendium/focusonvi olentcrimeandsexualoffences/yearendingmarch2015/chapter4intimatepersonalviolenceandpartner $\underline{\text { abuse }}$

Olver, M., Stockdale, K., and Wormith, J. (2011). "A meta-analysis of predictors of offender treatment attrition and its relationship to recidivism." Journal of Consulting and Clinical Psychology, 79(1), pp.6-21. doi:10.1037/a0022200

Olver, M., Stockdale, K., and Wormith, J. (2014). "Thirty years of research on the Level of Service Scales: A meta-analytic examination of predictive accuracy and sources of variability." Psychological Assessment, 26(1), pp.156-176. doi:10.1037/a0035080

Paulhus, D. (1999). Paulhus deception scales: User manual. New York, NY: Multi-health systems.

Pearson, D., Torgerson, D., McDougall, C., and Bowles, R. (2010). "Parable of two agencies, one of which randomizes." The ANNALS of the American Academy of Political and Social Science, 628, pp.11-29. doi:10.1177/0002716209351500

Pence, E., and Paymar, M. (1993). Education groups for men who batter: The Duluth model. New York, NY: Springer.

Piquero, A., Theobald, D., and Farrington, D. (2014). "The overlap between offending trajectories, criminal violence, and intimate partner violence." International Journal of Offender Therapy and Comparative Criminology, 58(3), pp.286-302. doi:10.1177/0306624x12472655 
RUNNING HEAD: DESIGN OF THE Up2U DOMESTIC ABUSE PERPETRATOR PROGRAMME

Ronan, G., Dreer, L., Dollard, K. and Ronan, D. (2004). "Violent couples: Coping and communication skills." Journal of Family Violence, 19, pp.131-137. doi:10.1023/B:JOFV.0000019843.26331.cf

Raynor, P. (1988). "Attitudes, social problems and reconviction in the STOP probation experiment." Howard Journal of Criminal Justice, 37(1), pp.1-15. https://doi.org/10.1111/1468-2311.00074

Scott, K., \& Wolfe, D. (2000). "Change among batterers: Examining men's success stories." Journal of Interpersonal Violence, 15(8), pp.827-842. https://doi.org/10.1177/088626000015008003

Serin, R., Lloyd, C., Helmus, L., Derkzen, D., and Luong, D. (2013). "Does intra-individual change predict offender recidivism? Searching for the Holy Grail in assessing offender change." Aggression and Violent Behavior, 18(1), pp.32-53. http://dx.doi.org/10.1016/j.avb.2012.09.002

Sherman, L., Smith, D., Schmidt, J., and Rogan, D. (1992). "Crime, punishment, and stake in conformity: Legal and informal control of domestic violence." American Sociological Review, 57(5), pp.680690. doi:10.2307/2095921

Smith, P., Gendreau, P., and Swartz, K. (2009). "Validating the principles of effective intervention: A systematic review of the contributions of meta-analysis in the field of corrections." Victims \& Offenders, 4, pp.148-169. https://doi.org/10.1080/15564880802612581

Stith, S., Smith, D., Penn, C., Ward, D., and Tritt, D. (2004). "Intimate partner physical abuse perpetration and victimization risk factors: A meta-analytic review." Aggression and Violent Behavior, 10(1), pp.65-98. http://dx.doi.org/10.1016/j.avb.2003.09.001

Stover, C., Meadows, A., and Kaufman, J. (2009). "Interventions for intimate partner violence: Review and implications for evidence-based practice." Professional Psychology: Research and Practice, 40(3), pp.223-233. doi:10.1037/a0012718

Sugarman, D. and Frankel, S. (1996). "Patriarchal ideology and wife assault: A meta-analytic review." Journal of Family Violence, 11, pp.13-40. doi:10.1007/BF02333338

Tapp, J., Fellowes, E., Wallis, N., Blud, L., and Moore, E. (2009). "An evaluation of the Enhanced Thinking Skills (ETS) programme with mentally disordered offenders in a high security hospital." Legal and Criminological Psychology, 14(2), pp.201-212. doi:10.1348/135532508X336178

Weisburd, D., Lum, C., and Petrosino, A. (2001). "Does research design affect study outcomes in criminal justice?" The ANNALS of the American Academy of Political and Social Science, 578, pp.50-70. doi:10.1177/000271620157800104 